\title{
Discerning and Addressing Environmental Failures in Policy Scenarios Using Planning Support System (PSS) Technologies
}

\author{
Brian Deal ${ }^{1}$ and Haozhi Pan ${ }^{2, *}$ \\ 1 Department of Landscape Architecture, University of Illinois, Champaign, IL 61820, USA; deal@illinois.edu \\ 2 Department of Urban and Regional Planning, University of Illinois, Champaign, IL 61820, USA \\ * Correspondence: hpan8@illinois.edu; Tel.: +1-217-418-8867 \\ Academic Editor: Tan Yigitcanlar \\ Received: 15 November 2016; Accepted: 19 December 2016; Published: 23 December 2016
}

\begin{abstract}
The environmental consequences of planning decisions are often undervalued. This can result from a number of potential causes: (a) there might be a lack of adequate information to correctly assess environmental consequences; (b) stakeholders might discount the spatial and temporal impacts; (c) a failure to understand the dynamic interactions between socio-ecological systems including secondary and tertiary response mechanisms; or (d) the gravity of the status quo, i.e., blindly following a traditional discourse. In this paper, we argue that a Planning Support System (PSS) that enhances an assessment of environmental impacts and is integral to a community or regional planning process can help reveal the true environmental implications of scenario planning decisions, and thus improve communal planning and decision-making. We demonstrate our ideas through our experiences developing and deploying one such PSS-the Land-use Evolution and impact Assessment Model (LEAM) Planning Support System. University of Illinois researchers have worked directly with government planning officials and community stakeholders to analyze alternate future development scenarios and improve the planning process through a participatory, iterative process of visioning, model tuning, simulation, and discussion. The resulting information enables an evaluation of alternative policy or investment choices and their potential environmental implications that can change the way communities both generate and use plans.
\end{abstract}

Keywords: environmental market failure; environmental planning; planning support systems; knowledge communication; plan making

\section{Introduction}

It has been suggested that among other attributes, good urban planning might function as a publicly-driven counterweight to potential market failures [1]. Similarly, as a specific planning disciplinary area, environmental planning might be viewed as a tool to counteract market forces that tend to result in environmentally unsustainable developmental patterns. For example, in a self-optimizing free market, no one will pay to avoid environmental externalities, especially those that are difficult to pin down or happen at stochastic spatial or temporal scales-unless there are planning or regulatory frameworks in place. These types of frameworks usually depend on environmental assessment processes and/or tools to uncover the environmental impacts of development or investment decisions and use planning-related measures to offset them [2,3]. In a typical planning process however, these assessments are usually poorly derived, poorly understood, and poorly applied. This can result from a number of potential issues. For example, there might be a lack of adequate information to correctly assess environmental consequences, or stakeholders might discount the spatial and temporal implications of the impacts. There may also be a failure to understand the dynamic and complex 
interactions between socio-ecological systems including secondary and tertiary response mechanisms. Finally, it might be that the gravity of the status quo, i.e., blindly following a traditional discourse, is the easiest and most compelling route for an un-informed group of stakeholders.

In this paper, we argue that if interpretations of environmental impacts are not comprehensively derived and sufficiently exposed to stakeholders, the true costs of development and investment decisions remain masked and will result in massive inefficiencies and ultimately environmental failure. We make this point by looking at environmental market failures within a planning context and the potential for planning support systems to counteract these failures. We do this by first connecting the literature on environmental market failures to planning practices (Section 2) in order to understand how these failures are typically manifested in planning-related processes. In Section 3, we suggest three steps that might be incorporated into the planning process in order to counteract these failures. These steps include: (1) a better understanding of the environmental issue; (2) providing more useful information to stakeholders; and (3) using planning processes to tackle spillover effects. In Section 4, we propose that the use of Planning Support Systems (PSS) can help support these steps. To illustrate the ideas in real-world planning practices, we introduce the implementation of the University of Illinois' Land-use Evolution and impact Assessment Model (LEAM) PSS in three application and deployment cases: Peoria, IL, St. Louis, MO, and McHenry County, IL. In each case, we demonstrate how the LEAM PSS was used to inform specific planning decisions in response to potential environmental systems degradation. In Section 5, we conclude the paper with a general discussion and conclusions on our ideas and lessons learned, including a brief discussion on the future of PSS technology in environmental assessment.

\section{The Realization of Environmental Market Failures in Planning}

In the literature on environmental market failures, environmental impacts are often considered undervalued; typically described as an externality or side effect instead of a primary or secondary cost [4] The consistent undervaluation of environmental costs often results in suboptimal decisions for individuals, organizations, or markets as a whole [4,5]. The root causes of these environmental market failures are difficult to pin down, although they are typically attributed to information imperfection, global externalities that do not affect local benefits, and/or complicated coordination of technology and ecological innovation. Andrew [5] points out that when market participants have sparse or uneven information, sub-optimal decisions are likely to ensue. This suggests that if information on environmental impacts are not known, market participants in routine development decisions are likely to generate environmental market failures [5-7].

Brueckner [7] considers planning as a potential remedy to the problem. We agree. We generally argue however, that if the environmental impacts of development are not sufficiently estimated, trusted, and/or objectively derived, planning will be unable to overcome the negative environmental impacts of market-driven forces. We also recognize that environmentally driven planning approaches can lead to undesirable and unintended environmental failures if done in a poor or incomplete way [7-9]. In the following, we discuss four potential ways in which urban planning typically fails to realize the true environmental implications of development or investment decisions (as noted above): (1) a lack of adequate information; (2) stakeholder spatial or temporal discounting; (3) a failure to understand the dynamic interactions between socio-ecological systems; or (4) the gravity of the status quo.

\subsection{A Lack of Adequate Information to Correctly Assess Environmental Consequences}

In the literature on market failures, imperfect information or information inefficiency are potential causes of failure. These are usually a product of asymmetric or incomplete access to information [5]. This means that certain types of information may be inaccessible to one party but not another, producing an asymmetrical transaction. An often used example is the used car market, where a seller of a used vehicle has much better information on the car's condition than a potential buyer. In this case the failure is due to the asymmetry of the information available to each side of the transaction 
causing a potential over-valuation of the vehicle's worth by the buyer. In planning and development projects, imperfect information is usually the result of information availability rather than asymmetry. This occurs when a complex development issue is difficult to assess or understand so that decisions are made based on incomplete information. This is especially true in the case of environmental impacts, where the issues may not be well defined, or even understood by the stakeholders or planners involved in the process-giving rise to suboptimal decision making and ultimately the host of environmental failures we currently see in our urban systems.

He et al. [10] point out that a persistent failure to deliver environmentally sustainable development solutions is closely linked to the separation of environmental assessment from the typical urban planning process. We suggest that insufficient adoption of environmental assessment is only part of the picture. A more essential problem is that most environmental assessment does not take full account of the environmental impacts of development. So that even when it is considered a part of a planning and development decision process, the delivery of incomplete information on impacts can lead to highly probable failure. For example, in a typical environmental assessment, a commercial development that engulfs a patch of agricultural land might associate the implications of the transaction only in terms of the primary impacts produced by the development (site-related impacts) or the loss of agricultural lands, which can be more regional in scope. If however, the development is proximal to ecologically sensitive areas, the development could have enormous ecosystem service impacts. This typifies hidden environmental costs that are often neglected by traditional environmental assessments.

\subsection{A Failure to Understand the Dynamic Interactions between Socio-Ecological Systems including Secondary and Tertiary Response Mechanisms}

Holmberg and Karl-Henrik [9] proposes that the non-linearity of markets often confound plans intended for sustainable development. For example, in the Laguna West master planned community in Sacramento County, CA, new urbanist and sustainable design principles were used as a basis for the development. Despite rigorous planning and analysis however, when the community began opening, the market for units in the community rose at a startling rate and subsequent phases subverted the planned economic diversification and many sustainability-oriented goals [11]. Such market-driven complexities can easily lead to a host of unexpected failures and shortcomings.

The general complexity of urban systems further undermines our ability to evaluate the real environmental costs of planning decisions. Urban planning problems are often referred to as "wicked problems" that are "inherently different from the problems that scientists and engineers deal with" [12]. Science and engineering-based approaches however, often deal with only primary impacts and fall way short of robust outcomes when applied to such wicked complexity. The non-linearity of future urban development patterns, and dependencies among developmental decisions often overwhelm the analytical capacities of typical environmental assessments, especially (most of) those that use static assumptions [13]. This difficulty in assessing secondary and tertiary (latent) impacts leads to incomplete information and confusion, which ultimately leads to environmental failure.

\subsection{Stakeholder Discounting of Spatial and Temporal Environmental Impacts}

Secondary and tertiary environmental costs typically spill over long spatial distances and trickle into distant futures. These long distances and time lines can lead to the problem of discounting. Discounting occurs when a value is subjectively lowered because it is removed or distant in terms of time, space, or socio-cultural relationships. Discounting is an important concept when discussing environmental sustainability (and climate change). Essentially the argument is that we should not discount the value of environmental resources (i.e., a healthy climate) for future generations because it will be just as valuable to them in 50 years as it is to us today. However, Fall [14] argues that we cannot predict how future generations will value environmental resources and that environmental crisis could alter the discount rates and slow the rate of environmental damage. Weitzman [15] presents a deductive argument for valuing environmental resources with a low discount rate for 
long-term planning projects showing that they are theoretically likely to produce the best return on investment. Hoel and Sterner [16] take this argument a step further and argue that the rising scarcity of environmental goods will also increase the relative cost and have direct effects of the discount rates. The idea of devaluing costs that are removed from a particular context in terms of space or time is a central problem in planning because it strikes at planning's very purpose: to adequately account for the costs associated with policy and investment strategies (i.e., plans) made within that context.

Berke and Conroy [6] argue that although plans are always linked to global concerns, "local plans should acknowledge that communities function within the context of global (and regional) environmental, economic, and social systems". Empirical data suggest that those links do not always lead to actions; that stakeholders tend to overlook and discount the spatial and temporal environmental costs of their plans. They further point out that the high discount rates that undervalue environmental costs with spatial and temporal distance help create plans with severe environmental impact spillovers. We argue that stakeholder discounting plays a large role in this phenomenon.

\subsection{The Gravity of the Status Quo, i.e., Blindly Following a Traditional, Growth-Oriented Discourse}

Some developers, businesses, and even some communities profit by maintaining the historical, developmental pattern status quo. Some argue that these patterns have typically been put in place at a time of 'unawareness' of their environmental implications [6,9]. Patterns of sprawl development for example, were started before their social, health and environmental ramifications were well known. In other words, some historic patterns may no longer be favorable when their associated environmental costs are assigned. Another useful example is energy production; much of our fossil-based energy infrastructure was developed before the actual costs of carbon emissions were known [5]. Now that we have a better sense of their true costs however, some of the infrastructure used in the energy industry is no longer viable. Similarly, urban development patterns continue to follow the sprawling, growth-oriented path initiated during the 1950s that make it increasingly difficult to bring our cities within what is considered ecologically sustainable and equitable [9].

In the sustainable design literature, Strategic Sustainable Development (SSD) is a proposed method that might tackle the complexity and uncertainties associated with sustainable developmental policies and thereby challenge the status quo [10]. SSD incorporates a set of techniques including life cycle analysis, indicator development, natural capital accounting, forecasting, emissions analysis, and backcasting to provide more accurate environmental assessment to current developmental trends and policy scenarios.

In summary, we suggest that in an urban planning context, environmental market failures might be attributed to a lack of knowledge of environmental impacts, a lack of understanding of secondary or tertiary impacts, and decision interactions, poor communication between spatially spread stakeholders, and a poor understanding of alternatives from current developmental paths. In the following section, we consider approaches to addressing these shortcomings through the use of spatially explicit Planning Support Systems (PSS). We posit that PSSs can help engage environmental decision-making in planning by providing more critical and useful information on the environmental implications of development decisions thereby helping stakeholders avoid planning-related environmental failures.

\section{Improving Planning Decisions with PSSs}

The use of PSSs is a relatively new addition to a long-running and persistent discourse on the role of technology in urban planning and policy-making $[17,18]$. One of the first comprehensive looks at planning PSS was assembled by Brail and Klosterman in 2001 [19]. Brail later writes more specifically on large-scale urban modeling systems [17]. Geertman and Stillwell followed, documenting best practices in PSS technology [18] with an update on the state of art in 2009 [20]. More recently, the emphasis has shifted to the management of information needs [21-23], use-based systems [24,25], and web-based strategies of information retrieval and delivery [23,26]. More recent conceptualizations also include Michael Batty's "Smart City" [24], described as "a fusion of ideas about how information 
and communications technologies might improve the functioning of cities". The idea revolves around the need to coordinate and integrate technologies that have synergies in operation but have been developed as separate entities_-much like what now might be considered a PSS.

One specific element typical of some spatially explicit planning Support Systems (PSSs), is a Land-Use Change (LUC) modeling core. These models are usually built with an intention to help planners and decision makers better understand spatial data, the dynamics and complexity of urban development patterns, and in some cases assess the impacts that changing urban patterns have on environmental, economic, and social systems. Although it has been more than 30 years since Cellular Automata (CA) technologies were tested in the development of these spatially explicit modeling cores [25], and more than 20 years since urban planners begin to adopt and adapt LUC models to develop first generation PSSs [27], these models have only recently become adaptable enough to be operationally used in support of planning.

\subsection{Reveailing Environmental Costs through PSSs}

Pioneers have now pushed PSS LUC model prototypes out of research labs and have begun to package the LUC models into operational applications with visual and online user interfaces. The Landuse Evolution and impact Assessment Model [28], WhatIf [29], and UrbanSim [30] are among three of the best operational examples in the US. These PSSs aim to enable non-experts with an ability to input data, operate, localize, and test their PSS LUC models with future potential scenarios, in some instances through web-based portals with simple mouse clicks. Some of these models are close to realizing this ideal (LEAM included). In our opinion however, in order to fully take advantage of the enormous benefits of PSSs within a structured planning process, a connection to knowledgeable modelers and planners is needed. These experts can: (a) facilitate the process and the technology needed to guide communities in applying the tools efficiently and effectively; (b) ensure the quality of PSSs inputs and outputs; (c) explain the implications of modeled outcomes (to non-technical audiences); and (d) they can help suggest implementation strategies in backcasting [9] and scenario analysis exercises. Generally, however, we believe these tools are fundamentally important for countering environmental market failures.

As previously noted, many hidden environmental costs are the result of a weakness in uncovering secondary (or tertiary) environmental impacts. This is compounded by an inability to understand the dynamics and interactions in and between impacts. LUC and PSS technologies are an effective means for addressing these issues. Spatially explicit PSSs bring together LUC models in an information delivery system (visualization interfaces) to provide planners and communities with critical knowledge of various dynamic systems and interactions that can facilitate more effective communicative planning approaches [19]. Infusing critical (environmental) knowledge to stakeholders and making (larger scaled) information available can engage a larger stakeholder group, that is capable and interested in understanding common environmental spillovers. The ready availability and democratization of information can also coerce communities and individuals to address the environmental externalities of their actions. Environmental impact information infused into public discussion through PSS technologies can also enable a more effecting weighing of the trade-offs that might emerge between economic benefits and environmental costs.

In addition, some planning and analysis techniques are greatly improved by PSS technologies $[26,31,32]$. The ability to easily perform backcasting analysis for example, can help plan-making processes achieve outside-the-norm envisioned, preferred futures rather than depending on a projection from the status quo perspective. These kinds of techniques are important for breaking historic, unsustainable, path dependent developmental patterns.

Given the potential of PSSs to aid urban planning in uncovering hidden environmental costs, the question becomes how these PSS tools become ubiquitous to real-life planning practices. The University of Illinois and the Landuse Evolution and impact Assessment Modeling Laboratory has had some success in operationalizing and implementing their Planning Support System in a variety of regions 
worldwide, most notably and successfully in the Midwestern US. In the following sections, we describe several examples of the LEAM operationalization process. These examples help to reveal some substantive ways in which the LEAM PSS has impacted the planning and policymaking and in the process helped to alleviate environmental market failures. First, through use-based PSS development and implementation. Next, by helping to counteract potential market distortions through useful information development and dissemination. Finally, through an ability to integrate seamlessly and positively affect the process of environmental assessment in the process of plan making. We also propose a future vision of PSS technologies that evolve from user-driven to user-awareness. We suggest this will enable them to be even more effective in practical environmental planning implementation.

\subsection{The LEAM PSS}

The need in planning and policy making to answer both 'what-if' and 'so-what' questions is fundamental to the LEAM PSS framework. The PSS consists of two major organizational parts: (1) a Land-Use Change (LUC) model—defined by a dynamic set of sub-model drivers that describe the local causality of change and enable an ability to test and play out potential 'what-if' scenarios; and (2) impact assessment models that facilitate interpretation and analysis of the modeled future land-use changes depending on local interest and applicability-these help to assess 'so-what' questions and explicate the potential implications of a modeled scenario.

LEAM LUC model utilizes a hybrid Cellular Automata (CA) approach. Similar to CA, LEAM utilizes a structured lattice surface (cells) with state-change conditions that evolve over time. The lattice is shaped by biophysical factors (such as hydrology, soil, geology and land form), and socioeconomic factors (employment, household structure, administrative boundaries, and planning areas). These factors, when taken in combination, provide a contoured lattice with high and low spots that represent each cell's probability of potential change in land use. Probabilities are predicated on local interactions (e.g., the accessibility of the cell to a given attractor), global interactions (e.g., the state of the regional economy), and other mechanisms of causation (e.g., social forces). Specific rules can be applied and tested. Controlling the constraints in the rule set can be used to produce diverse sets of planning scenarios. Unlike other large-scale efforts, LEAM works at a finely scaled resolution $(30 \times 30 \mathrm{~m})$ that includes cell-based micro models. This enables loosely and tightly coupled linking with other models that might operate at a different spatial scale, including regional macro socioeconomic models and transportation infrastructure and demand. The effect is that a wider range of potential 'what-if' scenario sets can be tested and assessed [26] LEAM has been both tightly and loosely coupled with other models that operate at various spatial and temporal scales including: economic forecasting models [33], bi-directional travel demand models [34]; ecosystem service models [34]; water quality models [35]; water quantity models [36]; and social cost models [37]. Coupling these models with LEAM dynamics and making the information useful through a 'use based' implementation process has helped decision makers make sense of the complex interactions between urban change and environmental systems.

\section{The LEAM Use-Based PSS Implementation}

In the LEAM implementation process, the LUC model evolves as an iterative process of data collection, model building, dialogue, visualization, and general presentation and access. Local planners, policy makers and stakeholders (convened by local planning entities and identified broadly as possible) provide feedback and input about the local salience and value of any given simulation. This feedback is gathered regularly and begins at project inception. It is used to more effectively capture the local condition, to provide a better local version of the tool and to inform local stakeholders about the tool and its uses. This form of use-driven modeling and system development, which takes place in very public forums, is what most distinguishes the LEAM approach [22]. The feedback and local dialogue elements are critical in the creation of useful PSS tools especially in terms of overcoming market distortions. Constant internal and external review and interaction are critical to informing both 
the modeler and the local stakeholders of modeled changes, improvements and scenario outcomes. Presenting this use-driven approach in publically accessible PSS visualization portals helps provide another layer of feedback and interaction. Consensus building is performed and achieved using typical planning procedures (see [29] for a more detailed discussion on use-based modeling and consensus building).

In applying this use-based model process we have found that LEAM can influence decision-making through various pathways [29]. In the following, we describe some specific pathways and their effect on the plan-making process in past LEAM applications. The three cases presented below: Peoria, IL, St. Louis, MO, and McHenry County, IL represent three ways in which the LEAM PSS has made significant impacts on the practice of planning. These include: counteracting distortions, facilitating dialogue, and integrated plan making for challenging the status quo.

\subsection{Counteracting Distortions in Peoria, IL}

Planning decisions take place over extremely long periods of time--sometimes involving different generations, over large distances. This raises questions of inter-generational and geographic equity. As noted previously, this is compounded by the fact that planning decisions have complicated spatial interactions and environmental impacts that are often secondary, or even tertiary. Environmental costs may accrue in one form, to one generation, in one part of the geography (community, state, nation, world); while the benefits accrue in a different form, for a different generation, in another part. Delivering objective, unbiased and apolitical information can help counteract these types of phenomena that can emerge in typical public planning processes [38].

Many of these issues are the result of an under-estimation of environmental impacts that are sometimes the result of information distortions. Information distortions are usually the product of local knowledge that is deeply situated in the web of accepted norms, meanings, and beliefs. If incorrect (distortions of actual causal relationships), their locally embedded nature makes information distortions difficult to overcome with traditional planning communication processes [39]. If left uncorrected, they can lead to problematic conclusions in public discussions. One example can be seen in local and personal discounting discussed above.

In our work, we argue that providing an ability to objectively test and evaluate current and future conditions can be a powerful tool for counteracting potential local distortions and poorly considered discounting that leads to costly future consequences. In an early LEAM application in Peoria, IL we helped provide those objective arguments for local and regional planners in a simple example.

In the early 2000s, the three counties surrounding Peoria, Illinois (Woodford, Tazwell, and Peoria) were witnessing significant conversion of very fertile and productive agricultural land to residential and commercial land-use. There was a distinct sense of unease about this trend, although there was no specific analytical proof for its existence. Woodford County in particular, was concerned about its agricultural heritage. The county outlined several strategies for preserving agricultural land. One particular strategy required a change in the county zoning ordinance that would require 40 -acre minimum lot size on current agricultural lands. At roughly the same time in a regional planning exercise, a number of simulations of future land-use change were being run for the tri-county region and reviewed and critiqued in public workshops [31]. These simulations established the extent and spatial distribution of future growth in a business-as-usual scenario described through maps and depictions of the impacts of this growth. Other scenarios explored included higher and lower growth rates and various public investments and policy ideas, including the proposed ordinance change in Woodford County. Figure 1 shows expected land-use outcomes in a 'business-as-usual' scenario. After our simulation, we used the land cover data provided by the county's planning board to assess loss of agricultural and ecological lands associated with future growth using 30-by-30-m resolution.

To discuss the simulation results, local planners held two big meetings and several smaller focused group meetings. Stakeholders involved in those public discussions included staff from Illinois Department of Natural Resources, citizens, non-government organizations (NGOs), local planners, 
and government entities. Public discussions on the 40-acre zoning requirement scenario revealed that the ordinance change would reduce consumption of agricultural land as intended but would also bring with it unexpected regional consequences. Compared to the business-as-usual scenario, the amount of agricultural land lost to development over thirty years with the proposed ordinance change dropped from 10,000 acres to 7000 acres. This was expected. Unexpectedly, when the proposed ordinance was included in a simulation, new development that would have been located in the agricultural area moved to environmentally sensitive bluffs along the Illinois River, resulting in the loss of 12,500 acres of forestland (Figure 1). This revelation changed perceptions of the proposed ordinance and the ordinance was put on hold until a ravine overlay district focused on protecting the river bluffs was put in place.

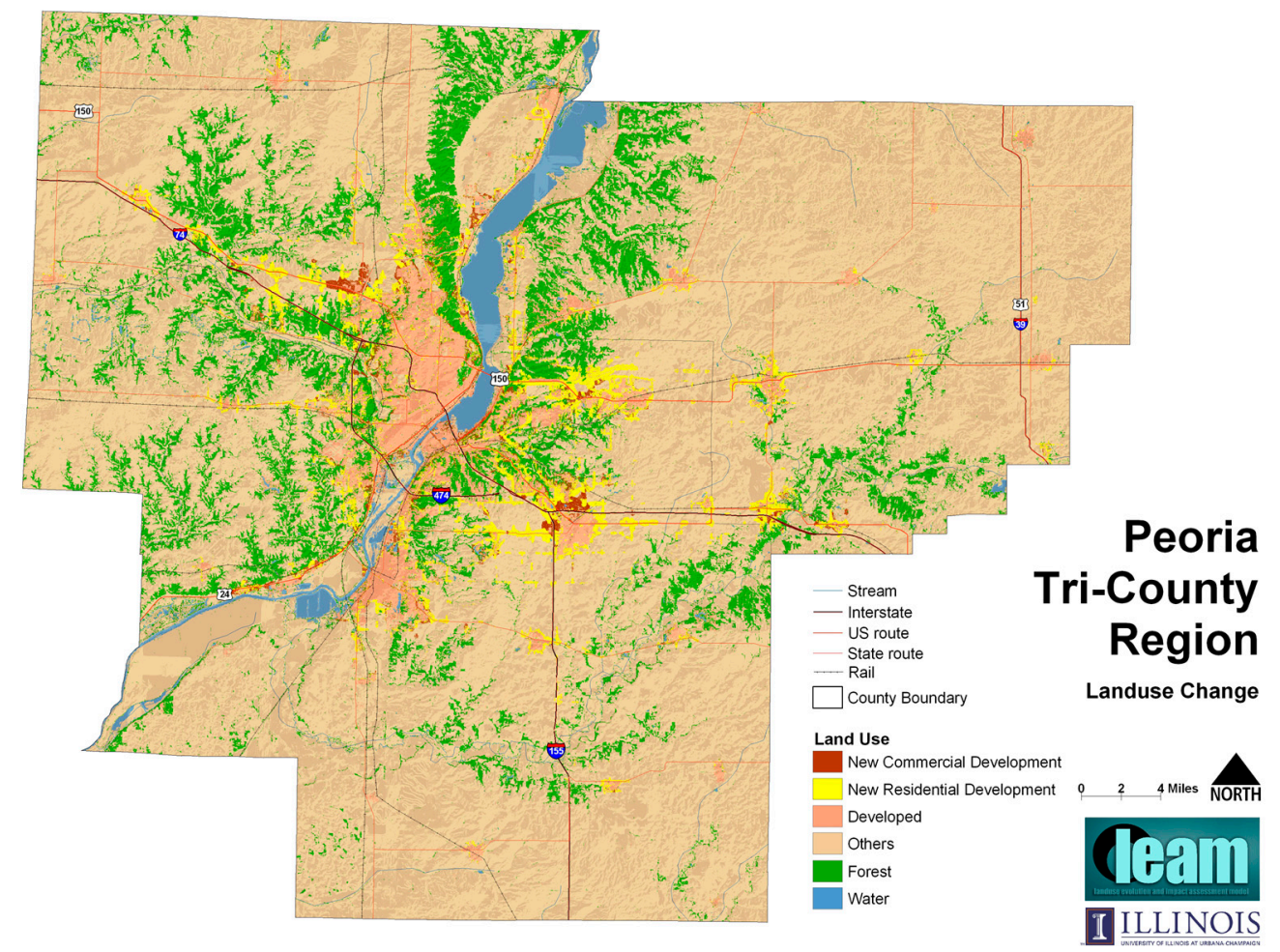

Figure 1. Land use outcomes in the Tri-County Region of Peoria in a 'business-as-usual' scenario. Yellow areas represent new residential developments; dark red patches are commercial. The arrow refers to the desirable bluff areas along the river.

Initially, any negative consequences of the proposed ordinance appear to have been discounted. Once people saw the simulations and understood the consequences of the proposed ordinance, this discount rate was substantially decreased to the point that protecting the bluffs became a higher priority.

It appears from the above case that explicating and elaborating on the future consequences of various public policy and investment choices may alter the extent to which these consequences are discounted by stakeholders in public deliberations. When future consequences are vaguely known and ill-defined, they are easily discounted. When potential consequences are represented in tangible and objective ways however, they make the familiar unfamiliar, they challenge habitual ways of thinking, and question what appears evident and taken for granted [40]. In short, they can counteract normative distortions.

\subsection{Facilitating Dialogue with the St. Louis Blueprint Model}

PSSs can assist planners in convening local stakeholders to discuss and validate environmental assessment results and in the process arouse a regional consciousness of the potential spatial and 
temporal spillover of environmental impacts. Geertman [41] points out that PSS tools can enhance participatory planning processes, because "a greater degree of access to relevant information will lead to the consideration of a greater number of alternative scenarios-which in turn will result in a better informed public debate". One project that exemplifies this idea is the application of LEAM to the two-state, eight-county region around St. Louis, Missouri (MO) [32,42]. In this project, we coupled various other models with LEAM to analyze the potential impacts of the land-use change results. Two in particular were a four step transportation model (that utilized over 2200 Transportation Analysis Zones, TAZ) to calculate travel time changes for each scenario, and a regional economic input-output model (conducted on a household level) that provided demand for space and assessed economic implications.

In 2003, the East-West Gateway Coordinating Council (the Metropolitan Planning Organization and Council of Governments for the St. Louis region), began to use LEAM (in a version later called the Blueprint Model) as a platform for encouraging a regional dialogue on issues of economic development, social equity and environmental sustainability. Instead of initializing the process with a lengthy model-building exercise, the initial focus was set on quickly producing a set of simulations. This quick-start process served two purposes: to quickly begin the process of engagement and build interest; and to collect information from the local stakeholders on the state of the local condition for adapting LEAM model to fit local conditions. These early simulations were subjected to public scrutiny in workshops, meetings and other public forums. Participants in these forums provided valuable insights into the dynamics of urban LUC in the region and a direction for future modeling efforts. Conducted on an annual basis, they also provided an excellent platform for dialogue among participants.

One early critique of the preliminary LEAM simulations presented was aimed at the way in which new development was being distributed across the two sides of the Mississippi River-the Illinois on the east, the Missouri on the west. Preliminary simulations showed considerable new developments in Illinois relative to Missouri; at the same time, the central business district (CBD) is in Missouri and has historically seen the bulk of new development. These simulations utilized posted travel speeds and did not take into account the difficulty of crossing the Mississippi River from Illinois into the CBD. When congested speeds were used to measure travel time (taking into account how traffic congestion makes portions of the region more or less attractive), simulated development shifted from Illinois to Missouri. A major factor was the effects of congestion on bridges and the approaches to them (bridges represent severe choke-points with very little opportunity for alternative routing). In the regional dialogue, this outcome highlighted the critical role played by bridges in the distribution of new development across the region.

The construction of a new Mississippi River bridge had been the subject of planning studies, preliminary design and environmental impact analysis for over 20 years in the region. A concerted civic and political effort to secure earmarked federal funding was only partially successful. The resulting funding shortfall called into question the original bridge proposal and how it would be implemented. Alternatives considered included covering the shortfall with a toll and constructing less expensive alternatives such as enhancing the capacity of an existing bridge; there was no regional consensus on the way forward. Facing a stalemate on the issue, the regional planning organization, the East-West Gateway Council of Governments (EWGateway) took the lead and sought to inject an analytical basis into the regional debate. In order to do this, however, it became crucial to go beyond traditional cost-benefit analyses and to jointly simulate and analyze future transportation and land-use consequences of the different choices.

Numerous simulations were created by coupling LEAM with a regional econometric input-output model (LEAMecon) and a regional travel demand model (TransEval). The land-use, economic and transportation outcomes in the simulations, and those of a baseline 'No-Build' simulation, were the basis for comparisons. Aggregate differences appear to be slight: building the bridge appears to slightly increase development in Illinois (Madison and St. Clair counties), while slightly decreasing 
development in Missouri (St. Louis and Jefferson counties). Interestingly, imposing a toll increased land development in far northwestern Missouri (St. Charles County). Figure 2 displays differences in LUC between the Full Build and No Build simulations at a finer resolution; red cells see more growth in the Full Build simulation, green cells see more growth in the No Build simulation. The map presents a more complex set of differences and suggests that aggregating to the county level masks greater change: while building the bridge facilitates greater land development in the Illinois side of the region and takes away from development on the Missouri side of the river, there are significant differences in development at the local level.

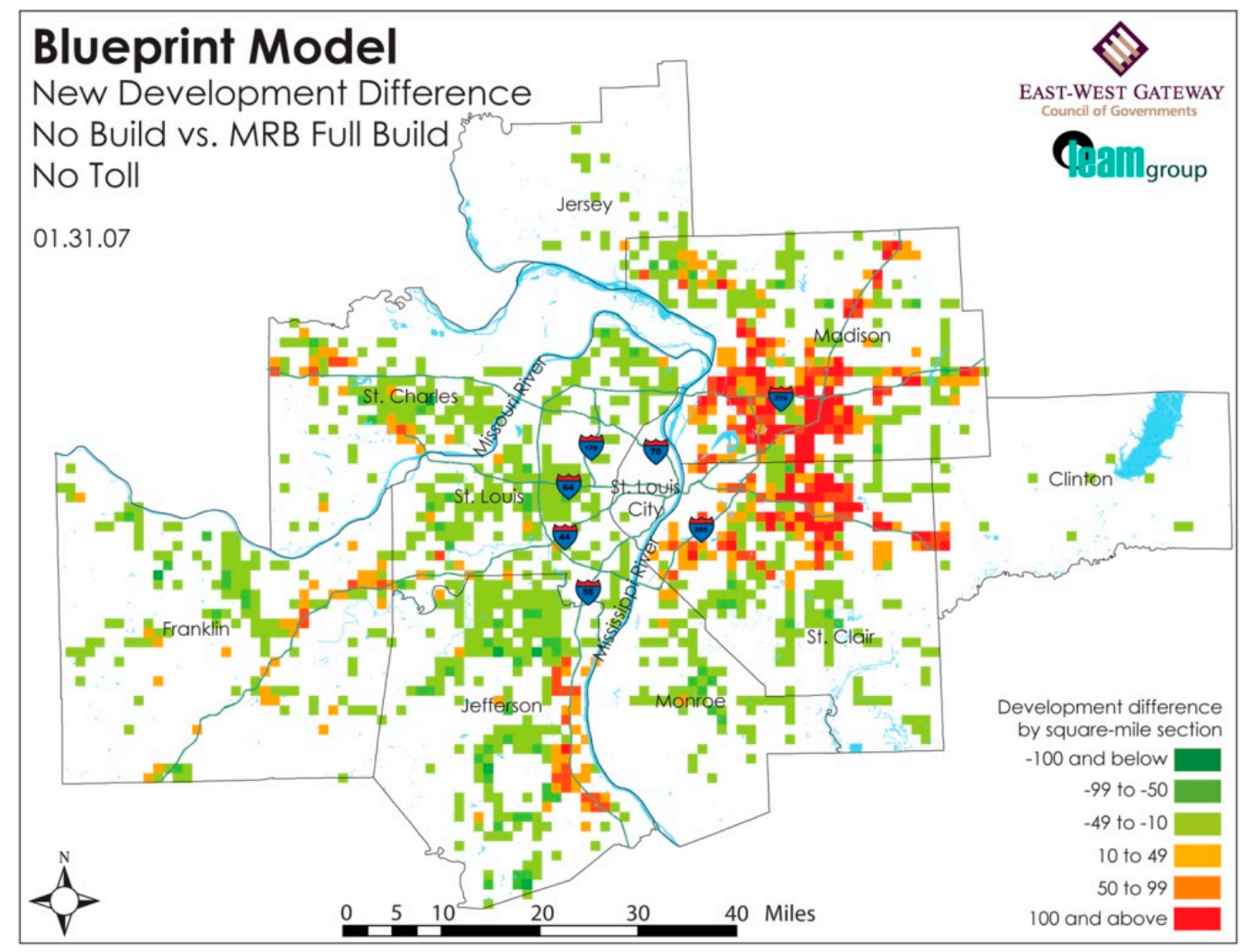

Figure 2. Differences between the Mississippi River Bridge Full Build (red) and No Build (green) simulations in the St. Louis Blueprint Model.

EWGateway convened three big public meetings and tens of smaller meetings to discuss the simulation results. As might be expected, discussions around these simulations were quite intense. Outcomes appeared counter-intuitive; imposing a toll on the bridge increased total travel times in the region. Working through the complex interactions suggested a striking explanation; the toll was diverting traffic to the other bridges across the river that do not impose a toll, increasing congestion on these bridges, and increasing travel times. This explanation brought into question the wisdom of using a toll to cover the budget shortfall. There were other insights generated: patterns of land use are likely to change if additional river crossings are built, therefore cooperative land-use policies and controls must be put in place in these areas to manage these impacts. Ultimately, however, only slight differences were uncovered even though the magnitude of the investment required for each of the scenarios tested was very different. This suggests that perhaps the lowest cost alternative is preferable, but it also suggests that demand-side tactics, such as investing in a better regional jobs-housing balance, might be more cost effective.

In this case, the LEAM PSS assisted planners in convening local stakeholders to discuss and validate each bridge scenario and their potential implications. The user-based process clearly facilitated 
a regional dialogue and aroused a regional consciousness of the potential spatial and temporal spillover effects. The process also helped challenged conventional thinking about the fundamental needs and benefits of the proposed investment.

\subsection{Planning for a Deviation from Current Developmental Path in McHenry County, IL}

In the previous discussion, including environmental assessment in planning processes and decision-making informed a public dialog so that participants had a better appreciation for the future environmental consequences of their public policy and public investment choices [33]. These planning processes however, are essentially forward looking exercises. Many similar processes that do not use PSS technologies rely heavily on projecting existing conditions into the future. They generally fail to capture changing paradigms or emergent behaviors. This often results in the continuation of existing developmental paths.

The use of PSS tools enable a broad range of multi-directional analysis that might be useful in analyzing or planning for structural change-including those needed to address a host of environmental market failures. The idea of backcasting using PSS technologies for example, has been shown effective in sustainable development planning [43]. Deal et al. [44] propose that backcasting from a desirable future state using PSS tools enables planners to step outside current developmental trends to test ideas and reexamine assumptions. Where a forecast projects an image of the future based on a current situation, a backcast starts at a point in time in the future and draws a developmental path back to the current condition. This is useful for plotting a path that responds to "how do we get there" kinds of questions from future states that might not emerge from existing trends.

A LEAM application in McHenry County, IL demonstrates a PSS-led backcasting exercise that helped the county understand how a desired deviation from their current developmental path might be achieved.

McHenry County, IL defines the northwest edge of the seven counties that make up the Chicago metropolitan region. It is approximately 60 miles northwest of downtown Chicago. It has a population of 318,000 . Its location and unique natural features create a quality-of-life that is attractive to many. Since 1990, the county's population has grown $40 \%$, averaging $2.3 \%$ growth annually. The previous land-use plan for the county was the McHenry County Land Use Plan 2010, which was compiled in 1993 and updated in 2000. However, McHenry County Regional Planning Commission (RPC) deemed this plan increasingly irrelevant and began to compile the McHenry County 2030 Comprehensive Plan in 2007 [26,45].

In 2007, with the help of the State of Illinois Department of Natural Recourses, the LEAM Laboratory began to build a PSS for the County. The original work was designed to assess the potential future implications that urban land use changes would have on the natural resources in the County. It was soon put to use to inform the discourse and test some of potential distortions emerging from their 2030 process [45]. The PSS development process first established a 'reference' or 'business-as-usual' scenario as a baseline for assessing the impacts of various land use policies being discussed. The reference scenario simulated LUC if current growth pattern trends continue to 2030. Other model scenarios were then compared to the reference scenario in order to understand the impact that the tested policies might have on various important county assets. LEAM was coupled with other impact models (as described above) to assess: land-use, water demand, water quality, wetlands, natural areas, agricultural uses, and groundwater protection (the list was determined by county stakeholders). Of particular interest to the County was the loss of important agricultural and ecological lands associated with future growth. These were evaluated linking LEAM to the Land Evaluation and Site Assessment (LESA) modeling framework from the Illinois Department of Agriculture [46].

The McHenry County Planning board convened more than 10 public meetings made up of a range of public interests, stakeholder groups, government employees and officials, and planners. The process revealed an early, major concern with the projected population forecast for 2030 that was derived using LEAMecon. This was the bellwether issue that underlay a larger conflict on the future of the 
County between pro and anti-growth advocates; one group of residents hoping to continue the past development trends and environmental groups urging protection of environmentally sensitive and agricultural lands. After lengthy discussions LEAM simulated a range of potential scenarios identified by the County Planning Board (18 prime scenarios) of future land-use patterns. The RPC identified various preferred outcome scenarios [26,45]. One such scenario, the Compact Contiguous Growth (CCG) composite scenario is shown in Figure 3. The difference between the reference scenario and the CCG composite scenario is on the left. Areas in blue receive more development in the CCG composite scenario; areas in red receive more development in the Reference scenario. A notable difference is seen in the southwest portion of the County. This is due to a limit that the CCG composite scenario places on the amount of vacant land available in that part of the county. The right shows an urban growth boundary that was also considered as part of the scenario analysis.
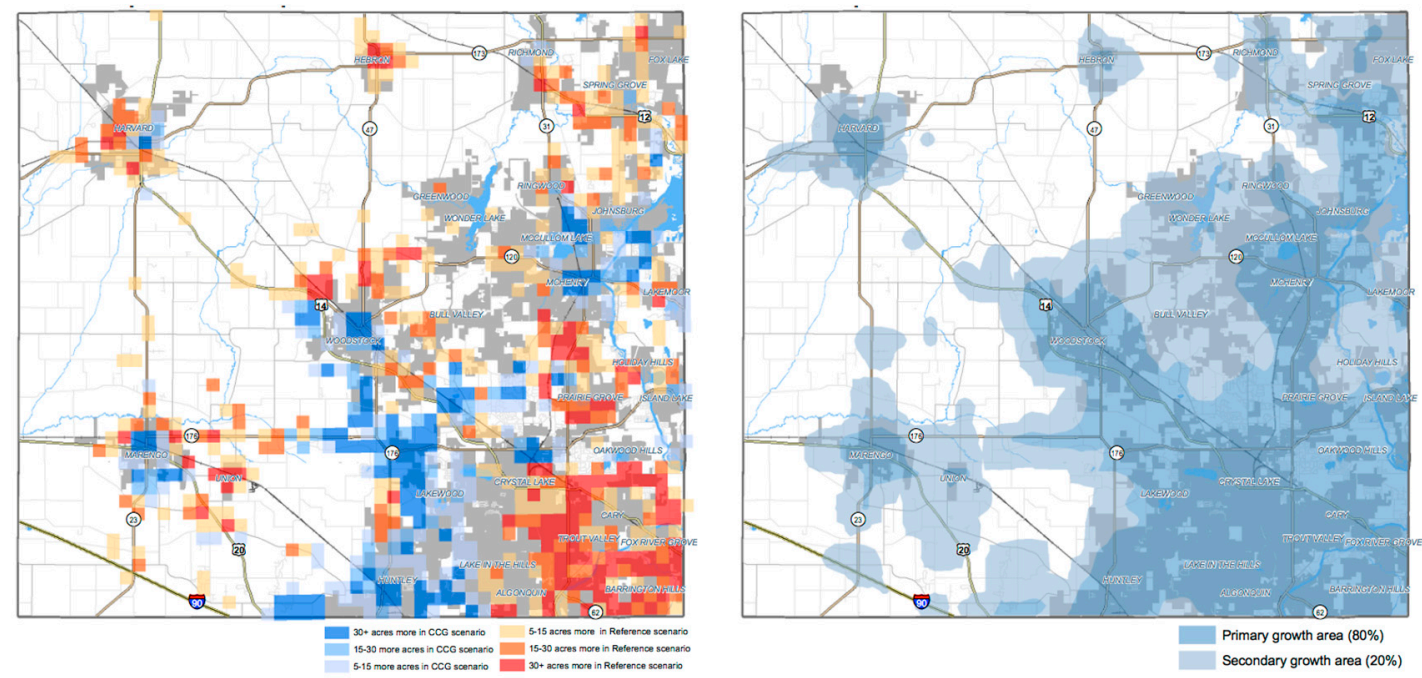

Figure 3. McHenry County Compact Contiguous Growth (CCG) scenario growth projection to 2030 compared with a reference scenario (left). Comparison using 1 mile $\times 1$ mile section scaling. Red cells are unique to the reference scenario; blue cells represent changes as a result of the CCG scenario. The right image shows as urban growth boundary that was also a part of the CCG scenario analysis.

The spatially and temporally explicit information generated by the LEAM PSS helped the McHenry County Regional Plan Commission (RPC) objectively assess the impacts of their proposed policies. For example, one scenario identified spatial locations where farmland and ecologically sensitive areas were identified as at risk [47]. With LEAM information, the RPC could specify where to set up ecological/agriculture preservation districts to prevent a disruption of the critical areas.

The process represents a typical PSS backcasting exercise. First, a desirable outcome was established-in this case, minimizing agricultural and ecological land losses. Backcasting how to achieve this desirable outcome required an analysis of the complex interactions between a host of variables, so that many multiple model iterations were examined in order to understand exactly what this preservation meant to county stakeholders. Once these were unraveled, a coherent set of policy levers were developed for how these outcomes for the future might be achieved. In this case agriculture productivity was closely tied to the introduction of a new (and also desired) transportation investment (a new interchange conflicted with highly productive agricultural lands). The LEAM PSS provided useful spatially explicit information on where, when, and how to plan for an alternative, desirable future that was just outside current development patterns.

The LEAM PSS enabled a 'continuous planning' process to take shape in the county. The spatial and aspatial data created for the PSS allows the community to continuously interact with the data and models associated with the plan (a visualized interactive tool is shown in Figure 4). It is now a living comprehensive plan where critical questions can be examined, progress on critical issues can be 
updated and communicated, and success or failure can be determined and re-assessed. We suggest this type of tool and process are critical for challenging existing (and unsustainable) growth and development practices and challenging the status quo.

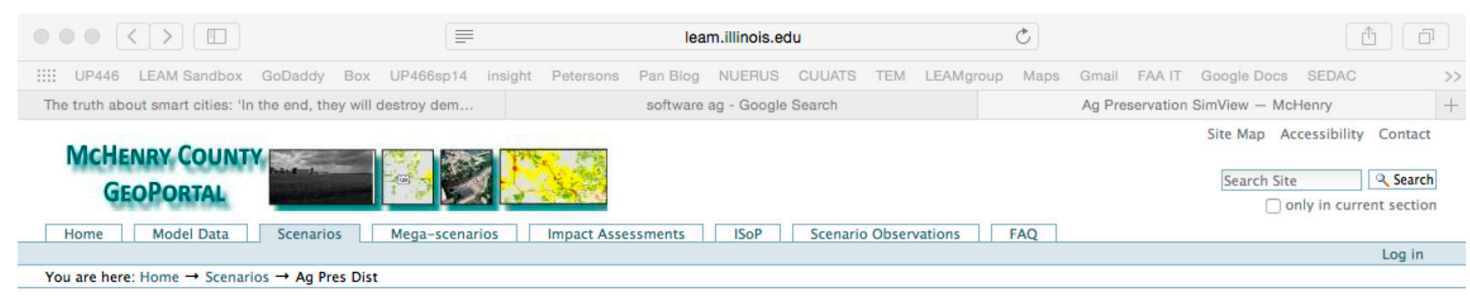

Ag Preservation SimView

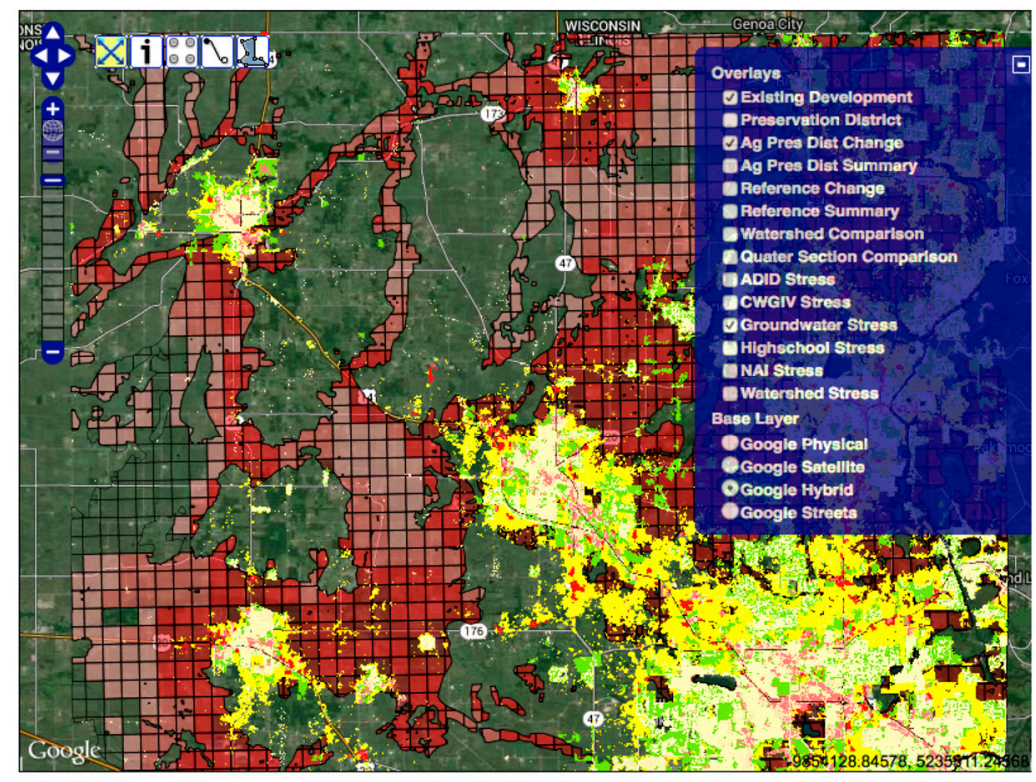

Figure 4. The LEAM PSS's 'GeoPortal' for McHenry County. The center is the map viewer window with overlay results viewed on an interactive google map. On the right is a legend for the displayed maps. The viewer displays a forecasted agricultural preservation scenario and its associated groundwater stress. Yellow and bright right cells demonstrate future growth scenario; darker red cells (big cells) represent groundwater stress associated with the growth.

\section{Discussion and Conclusions}

In this paper we posit that if environmental impacts are not sufficiently exposed in the planning process, environmental market failures will likely materialize. We note that this can take several forms including: a lack of adequate information, stakeholder discounting, a failure to understand complex interactions, or by following a traditional, growth-oriented path. We argue that the use of dynamic and complex systems models that are able to effectively derive a truer picture of the environmental impacts of a given scenario plan can help offset some of this failure. We then demonstrate how the operational deployment of the LEAM model and PSS in real world planning settings supports this notion. We described several communities that were able to avoid decision traps that could bring about otherwise unseen environmental impacts.

In Peoria, IL we showed that providing useful information on the future consequences of planning decisions help alter stakeholder discounting. From our experience, we conclude that when potential consequences are represented in tangible and objective ways they can challenge habitual ways of thinking and help counteract normative distortions. 
In the St Louis, MO metro area, the LEAM PSS assisted planners in convening local stakeholders and facilitating a regional dialogue. This helped raise a regional awareness of the potential spatial and temporal spillover effects and challenged conventional thinking on the proposed investment.

In McHenry County, IL the LEAM PSS enabled a county wide dialogue in a 'continuous planning' process where the data and models associated with the plan can be continuously accessed, examined, and communicated so that success or failure of each proposed policy can be determined and re-assessed. We conclude this is critical for challenging existing (and unsustainable) planning practices.

The following are some additional observations and lessons learned from our experiences in PSS deployment and environmental assessment.

\subsection{The Process of Constructing Useful Planning Support Models Is More Important Than the Modeled Results}

One important lesson learned is that in order to foster local thought experiments and discussion, it may not be necessary to wait until model results are highly calibrated and fine-tuned. In fact, we argue that planning and decision impact can be more important than model accuracy. Preliminary results that can be presented early in the planning process and are easily modified can serve to ignite regional dialogue. For example, the presentation of both favorable and unfavorable scenarios in terms of environmental impacts would be useful in helping a community understand and articulate their preferences. This articulation can help stakeholders and planners communicate with each other as well as steer policy toward achieving important sustainability goals that are sometimes difficult to express. This does not absolve planners from providing accurate depictions-especially when challenging accepted norms however. At some point in the process reliable and trust worthy information is required. But it does suggest that even 'quick and dirty' results can be very useful when planners, stakeholder representatives, and decision-makers work cooperatively to interpret them through the lens of expertise and local perspective.

\subsection{The Physical Representation of Information Matters}

In operationalizing LEAM, we have been extremely careful about how we represent and display the numerous graphic and visual representations that are created. We take great pains to explain the logic of these representations to stakeholders involved. While we have to this point, limited ourselves to maps and graphs, we have developed a variety of ways to represent spatial and temporal data [42] — roughly adhering to the six I's of Senbel and Church [48]—information, inspiration, ideation, inclusion, integration, and independence. While we recognize that any cartographic representation is necessarily selective truth-telling, we also recognize that visual representations are critical for affecting stakeholder understanding and for unraveling the problem of discounting the future.

\subsection{User-Driven, Use-Driven, and User-Awareness in PSS Deployment}

User-driven models (such as WhatIf? and UrbanSIM) are packaged into software that can be run with some basic skills sets by planners or policy makers. Use-driven models such as LEAM are created for specific projects at specific instances, and sometimes built to answer specific questions. Use-based models involve modelers, contextual experts, and planners to help build operate and explain the models in the planning process. Stakeholders and citizens are also critical to their development and deployment. They provide important, but difficult to obtain local, historical knowledge, insights about local dynamics, and intimate knowledge of local social constructs. They also provide the specific goals and visions for the future that are so essential to the planning and modeling process.

Use-driven and user-driven PSS models are not mutually exclusive however, component pieces of both are useful. For example, user-based interfaces allow non-experts to directly modify model factors according to their understandings of their locality and generate their own results. Modelers should be on hand to interpret those results and facilitate public discussions based on different model results.

User-aware PSSs are a next-generation process that combines use/user-driven PSS models. User-aware PSS can adjust its user-interface to different users (modeling experts or layman users) 
and communicate diverse user-inputs with each other in the system. This can make future PSS operationalization more democratic and interactive.

\subsection{Post-Plan Involvement Is Also Important for Operationalizing a PSS}

Currently, PSS-generated information is mainly utilized during the pre-implementation phase of the planning process. Although monitoring can be an important component of plan implementation (that sometimes can determine the success or failure of a plan), due to time constraints it is not often feasible for planners to collect new data, look back and analyze previous plans. A next generation PSS might automate this process so that "actual" emerging developments and real-time environmental impacts can be included in development of scenarios and plans. As the time and effort for post-plan monitoring are conserved, planners and modelers can afford additional time with the communities to ensure that implementation can more closely follow the plan intent. This can also be useful in helping stakeholders to understand the dynamic interactions between socio-ecological systems and socio-physical decisions.

\subsection{The Future of PSS Technology in Environmental Assessment}

We see a general need for information and planning systems which current PSS technologies provide do not meet; especially in the area of environmental assessment. We need smart planning support systems that possess basic self-awareness with respect to their data and users. These should be capable of learning, of spatial and temporal reasoning, of understanding system integration rules, and be able to adequately address environmental impacts from a broad perspective. More specifically, and in the spirit of the above, these technologies should be capable of producing reasonable and adequate environmental impact information that can reduce stakeholder spatial and temporal discounting and challenge the traditional and unsustainable status quo.

Author Contributions: Both authors (Brian Deal and Haozhi Pan) contributed to the paper by collecting cases and writing the content.

Conflicts of Interest: The authors declare no conflict of interest.

\section{References}

1. Klostermann, R. Argument for and against Planning. Town Plan. Rev. 1985, 56, 5-20. [CrossRef]

2. Randolph, J. Environmental Land Use Planning and Management; Island Press: Washington, DC, USA, 2004.

3. Marsh, W.M. Landscape Planning: Environmental Applications; John Wiley and Sons: Hoboken, NJ, USA, 2005.

4. Jaffe, A.B.; Newell, R.G.; Stavinsc, R.N. A tale of two market failures: Technology and environmental policy. Ecol. Econ. 2005, 54, 164-173. [CrossRef]

5. Andrew, B. Market failure, government failure and externalities in climate change mitigation: The case for a carbon tax. Public Adm. Dev. 2008, 28, 393-401. [CrossRef]

6. Berke, P.R.; Conroy, M.M. Are we planning for sustainable development? An evaluation of 30 comprehensive plans. J. Am. Plan. Assoc. 2000, 66, 21-33. [CrossRef]

7. Brueckner, J.K. Urban sprawl: Diagnosis and remedies. Int. Reg. Sci. Rev. 2000, 23, 160-171. [CrossRef]

8. Naess, P. Urban planning and sustainable development. Eur. Plan. Stud. 2001, 9, 503-524. [CrossRef]

9. Holmberg, J.; Karl-Henrik, R. Backcasting from non-overlapping sustainability principles-A framework for strategic planning. Int. J. Sustain. Dev. World Ecol. 2000, 7, 291-308. [CrossRef]

10. He, J.; Bao, C.-K.; Shu, T.-F.; Yun, X.-X.; Jiang, D.; Brwon, L. Framework for integration of urban planning, strategic environmental assessment and ecological planning for urban sustainability within the context of China. Environ. Impact Assess. Rev. 2011, 31, 549-560. [CrossRef]

11. Katz, P.; Scully, V.J.; Bressi, T.W. The New Urbanism: Toward an Architecture of Community; McGraw-Hill: New York, NY, USA, 1994; Volume 10.

12. Rittel, H.W.J.; Webber, M.W. Dilemmas in a General Theory of Planning. Policy Sci. 1973, 4, 155-169. [CrossRef] 
13. Barredo, J.I.; Kasanko, M.; McCormick, N.; Lavalle, C. Modelling Dynamic Spatial Processes: Simulation of Urban Future Scenarios through Cellular Automata. Landsc. Urban Plan. 2003, 64, 145-160. [CrossRef]

14. Fall, E.H. The Worst-Case Scenario and Discounting the Very Long Term; HAL: Bangalore, India, 2006.

15. Weitzman, M.L. Why the far-distant future should be discounted at its lowest possible rate. J. Environ. Econ. Manag. 1998, 36, 201-208. [CrossRef]

16. Hoel, M.; Sterner, T. Discounting and relative prices. Clim. Chang. 2007, 84, 265-280. [CrossRef]

17. Brail, R.K. Planning Support Systems for Cities and Regions; Lincoln Institute of Land Policy: Cambridge, MA, USA, 2008.

18. Geertman, S.; Stillwell, J. Planning Support Systems in Practice; Springer: New York, NY, USA, 2003.

19. Brail, R.K.; Klostermann, R.E. Planning Support Systems: Integrating Geographic Information Systems, Models, and Visualization Tools; ESRI Press: Redlands, CA, USA, 2001.

20. Geertman, S.; Stillwell, J. Planning Support Systems: An Introduction; Springer: Berlin, Germany, 2009.

21. Brömmelstroet, M.T. Equip the warrior instead of manning the equipment: Land use and transport planning support in the Netherlands. J. Transp. Land Use 2010, 3, 25-41.

22. Deal, B. Sustainable Land-Use Planning: The Integration of Process and Technology; VDM Verlag: Saarbrücken, Germany, 2008.

23. Budthimedhee, K.; Li, J.; George, R. ePlanning: A Snapshot of the Literature on Using the World Wide Web in Urban Planning. J. Plan. Lit. 2002, 17, 227-246. [CrossRef]

24. Batty, M. Smart Cities and Big Data: How We Can Make Cities More Resilient; Keynote Address at the Joint AESOP-ACSP Congress: Dublin, Ireland, 2013.

25. White, R.; Engelen, G. Urban systems dynamics and cellular automata: Fractal structures between order and chaos. Chaos Solitons Fractals 1994, 5, 563-583. [CrossRef]

26. Deal, B.; Pallathucheril, V. A Use-Driven Approach to Large-Scale Urban Modelling and Planning Support. In Planning Support Systems Best Practice and New Methods; Springer: Dordrecht, The Netherlands, 2009; Volume 95, pp. 29-51.

27. Geertman, S.; Stillwell, J. Planning support systems: An inventory of current practice. Comput. Environ. Urban Syst. 2004, 28, 291-310. [CrossRef]

28. LEAM Lab. LEAM Portal. Available online: http://www.leam.illinois.edu/ (accessed on 22 December 2016).

29. What if? Inc. Welcome to What if?TM 2.0 2015. Available online: http://www.whatifinc.biz/ (accessed on 22 December 2016).

30. UrbanSim. Available online: http://www.urbansim.com/urbansim/ (accessed on 22 December 2016).

31. Deal, B.; Pallathucheril, V. The Land Evolution and Impact Assessment Model (LEAM): Will it play in Peoria? In Proceedings of the 8th International Conference on Computers in Urban Planning and Urban Management, Sendai, Japan, 27-29 May 2003.

32. Deal, B.; Pallathucheril, V. Simulating Regional Futures: The Land-use Evolution and impact Assessment Model (LEAM). In Planning Support Systems for Cities and Regions; Brail, R., Ed.; Lincoln Institute for Land Policy: Cambridge, MA, USA, 2008; pp. 61-84.

33. Pallathucheril, V.; Deal, B. Communicative Action and the Challenge of Discounting. In Proceedings of the 53rd Annual Conference of the Association of Collegiate Schools of Planning, Cincinnati, OH, USA, 1-4 November 2012.

34. Deal, B.; Kim, J.H.; Hewings, G.J.; Kim, Y.W. Complex urban systems integration: the LEAM experiences in coupling economic, land use, and transportation models in Chicago, IL. In Employment Location in Cities and Regions; Springer: Berlin, Germany, 2013; pp. 107-131.

35. Choi, W.; Deal, B.M. Assessing hydrological impact of potential land use change through hydrological and land use change modeling for the Kishwaukee River basin (USA). J. Environ. Manag. 2008, 88, 1119-1130. [CrossRef] [PubMed]

36. Sun, Z.; Deal, B.; Pallathucheril, V.G. The land-use evolution and impact assessment model: A comprehensive urban planning support system. URISA J. 2009, 21, 55-62.

37. Deal, B.; Schunk, D. Spatial dynamic modeling and urban land use transformation: A simulation approach to assessing the costs of urban sprawl. Ecol. Econ. 2004, 51, 79-95. [CrossRef]

38. Forester, J. The Argumentative Turn in Policy Analysis and Planning; Duke University Press: Durham, NC, USA, 1993. 
39. Stein, S.M.; Harper, T.L. Creativity and Innovation Divergence and Convergence in Pragmatic Dialogical Planning. J. Plan. Educ. Res. 2012, 32, 5-17. [CrossRef]

40. Fischler, R. Communicative planning theory: A Foucauldian assessment. J. Plan. Educ. Res. 2000, 19, 358-368. [CrossRef]

41. Geertman, S. Participatory planning and GIS: A PSS to bridge the gap. Environ. Plan. B Plan. Des. 2002, 21, 21-35. [CrossRef]

42. Deal, B.; Pallathucheril, V. Developing and Using Scenarios. In Engaging the Future: Forecasts, Scenarios, Plans, and Projects; Hopkins, L.D., Zapata, M.A., Eds.; Lincoln Institute for Land Policy: Cambridge, MA, USA, 2007; pp. 222-242.

43. Deal, B.; Jenicek, E.; Goran, W.; Myers, N.; Fittipaldi, J. Strategic Sustainability Assessment. Geol. Soc. Am. Spec. Pap. 2011, 482, 41-57.

44. Deal, B.; Pallathucheril, G.; Pan, H. Planning Support Systems in the Rear View Mirror. In Proceedings of the 49th Annual Conference of the Association of Collegiate Schools of Planning, Philadelphia, PA, USA, 30 October-2 November 2014.

45. McHenry County Regional Planning Commission McHenry County 2030 Comprehensive Plan. 2010. Available online: https://www.co.mchenry.il.us/county-government/departments-j-z/planning-development/2030beyond/project-introduction (accessed on 13 December 2016).

46. Coughlin, R.E.; Pease, J.R.; Steiner, F.; Papazian, L.; Pressley, J.A.; Sussman, A.; Leach, J.C. The status of state and local LESA programs. J. Soil Water Conserv. 1994, 49, 6-13.

47. McHenry County Farm Bureau Update on the Regional Planning Commission's 2030 Plan, by Jim McNutt. 2008. Available online: http://www.mchenrycfb.org/drupal/news/update-regional-planningcommission\%E2\%80\%99s-2030-plan-jim-mcnutt (accessed on 13 December 2016).

48. Senbel, M.; Church, S.P. Design empowerment: The limits of accessible visualization media in neighborhood densification. J. Plan. Educ. Res. 2011, 31, 423-437. [CrossRef]

(C) 2016 by the authors; licensee MDPI, Basel, Switzerland. This article is an open access article distributed under the terms and conditions of the Creative Commons Attribution (CC-BY) license (http://creativecommons.org/licenses/by/4.0/). 